\title{
O DIREITO DO AUTOR NA QUALIDADE DE FATOR DE PROTECCÃO FUNDAMENTAL DA OBRA: CARACTERÍSTICAS E RESPONSABILIDADES MORAIS E PATRIMONIAIS
}

\section{COPYRIGHT PROTECTION AS FACTOR OF FUNDAMENTAL CREATED ON WORK: FEATURES AND MORAL AND PATRIMONIAL RESPONSIBILITY}

\author{
Eulália Xavier Ribeiro' \\ Especialista em Gestão e Business Law \\ Instituições Nelly Falcão de Souza - Manaus (AM) - Brasil
}

RESUMO: O Direito do Autor, como fator de proteção dos direitos morais e patrimoniais do autor sobre a obra criada, busca sua fundamentação teórica em autores como: Carlos Alberto Bittar e Manuella Santos. Este estudo analisa os direitos autorais a partir de um estudo minucioso sobre as noções básicas do Direito de Autor, abordando sua conceituação, versando sobre a parte histórica; estabelecendo os fundamentos sobre as diferenças entre os Direitos Morais e os Direitos Patrimoniais de autor. Para referendar o estudo jurídico foram realizadas pequisas jurisprudenciais para obtenção de casos julgados acerca do assunto, com o firme propósito de disseminar os direitos garantidos na legislação vigente no Brasil, bem como nas convenções internacionais de proteção dos direitos de autor. As abordagens metodológicas são: a revisão bibliográfica; e os dados secundários obtidos nos Tribunais de Justiça e no Superior Tribunal de Justiça, objetivando com isso a resposta à hipótese da pesquisa.

PALAVRAS-CHAVE: Direito Autoral, Direitos Morais, Direitos Patrimoniais.

ABSTRACT: The copyright law, as a protective factor of moral and economic ri-

${ }^{1}$ Graduada e Pós Graduada em Gestão e Business Law pelo MBA Executivo da Vice-Reitoria de Pós Graduação e Pesquisa, no Programa de Pós graduação Lato Sensu em Direito das Instituições Nelly Falcão de Souza - INFS - em parceria Escola de Direito do Rio de Janeiro - FGV Direito Rio realizado on line e nas dependências da primeira parceira, em Manaus, no Amazonas. $\mathrm{O}$ artigo insere-se na Linha Editorial da Revista: Direitos Findamentais e suas dimensões. Diretora Executiva da VR Assessoria do Amazonas. E-mail: eulalia@vrassessoria.com.br 
ghts of the author of the work created, seeking its theoretical foundation such as Carlos Alberto Bittar and Manuella Santos. This study analyzes the copyright from a detailed study on the basics of copyright law, addressing its concept, dealing with the historic part; laying the foundation about the differences between Moral Rights and the Rights of Equity author. To endorse the legal study conducted searches jurisprudence to show cases tried on the subject, with the firm intention of disseminating the rights guaranteed in the current legislation in Brazil and in international conventions on copyright protection. The methodological approaches are: a literature review; and secondary data obtained in the States Courts of Justice and the Brazilian Superior Court, aiming thus the answer to the hypothesis of the research.

KEYWORDS: Copyright Law, Moral Rights, Equit Rights.

\section{Introdução}

Observa-se que o desconhecimento por muitos autores faz com que pessoas e empresas usufruam de suas obras, uns por total desconhecimento da proteção que lhes garante a legislação brasileira e acordos internacionais, outros por falta de coragem de enfrentar um processo judicial que muitas vezes pode impedi-lo de negociar outras obras em detrimento de uma pendência jurídica com uma ou outra empresa. Nos exemplos de matérias julgadas, em destaque neste estudo, tanto em direito moral, quanto em direito patrimonial, constata-se a realidade existente, o desrespeito aos direitos de autor, mas cabe a pesquisa para o estudo deste tema, com o intuito de minimizar este tipo de atitude e incentivar continuamente que prevaleça o respeito pelos direitos de autor na sociedade atual.

Justifica-se a abordagem do tema ora proposto, pelo desconhecimento da maioria dos autores quanto ao valor moral e patrimonial de sua obra, trazendo uma discussão pormenorizada sobre o assunto, pois se observa que é usual no mercado brasileiro e principalmente em mercados menos desenvolvidos, a usurpação dos direitos de autor em detrimento dos interesses de pessoas e empresas que, no interesse de gerar faturamento, não se preocupam em contratar, pedir autorização de uso, pagar ou dar crédito a quem de direito: o autor da obra.

Nota-se, desta forma, que o autor não tem o seu devido valor e reconhe- 
cimento sobre a sua obra, gerando um problema social difícil de administrar. Diante deste fato, se deve trabalhar a conscientização dos autores, das pessoas de um modo geral e das empresas, em busca de mudança desta cultura no Brasil e principalmente em mercados menos desenvolvidos.

Direito de autor é um assunto indiscutivelmente abordado em todos os segmentos de atuação do mercado e se faz necessário um estudo acerca deste tema, pois se depara corriqueiramente com dúvidas quanto ao direito efetivo de autor. 0 exemplo deste tipo de dúvida pode-se citar casos como os que acontecem no segmento publicitário e de produção de filmes, onde há prejuízo de muitos profissionais que são ludibriados por muitas agências de publicidade, como também por clientes que se utilizam de fotografias, textos e filmesque em sua maioria não tem a autoria de seus trabalhos creditados e/ou reconhecidos aos seus autores, prejudicando seus direitos sobre a obra criada.

Deve-se este fato em sua maioria, a problemática devido ao desconhecimento do autor quanto aos seus direitos, como também pela falta de cultura em alguns mercados ao reconhecimento do trabalho do autor.

Em se tratando de um tema de suma importância para o convívio em sociedade,pretende-se atingir nesta pesquisa os objetivos geral e específicos propostos.

Como objetivo geral se busca: estudar meios pelos quais o Direito de Autor seja ainda mais difundido na sociedade em sua forma de proteger e reconhecer o direito efetivo de autor sobre suas obras; e específicos: (i) Apresentar o escorço histórico sobre o Direito de Autor; e (ii) Analisar os direitos morais e patrimoniais dos autores e suas características básicas e exemplos julgados envolvendo a temática.

A metodologia da pesquisa utilizada neste trabalho é a revisão de literatura. Foram realizadas pesquisas bibliográficas da literatura jurídica, além da análise da Lei n. 9.610, de 19 de fevereiro de 1998, que alterou, atualizou e consolidou a Legislação sobre direitos autorais, após a promulgação da atual Constituição da República Federativa do Brasil. Ademais, realizou-se pesquisa de dados secundários nos Tribunais de Justiça a fim de apresentar julgados, exemplos sobre o tema em análise, particularmente visando conscientização da sociedade na valorização e no reconhecimento dos autores e de suas obras. Assim, pretende-se atingir os objetivos: geral e específicos, propostos na pesquisa. 


\section{Noção geral do direito do autor}

Este capítulo versará acerca do Direito de autor, com o intuito de aprofundar o conhecimento dos benefícios que a legislação assegura ao autor em busca de maior proteção de seus direitos. 0 conhecimento da sociedade brasileira precisa avançar no que diz respeito a este assunto, nota-se que tal conhecimento ainda está muito distante do que assegura a legislação vigente no Brasil e nas convenções Internacionais de que tratam o Direito de Autor.

\subsection{Escorço Histórico-Legislativo}

Fábio Vieiradestaca que sempre houve a necessidade de se legislar de forma comum sobre o Direito de Autor, vez que as expressões artística, científica e literária, sob qualquer forma, constituem ponto de união entre as culturas, tendendo, por conseguinte, ao rompimento de barreiras. 0 autor destaca também, o escólio de Plinio Cabral: "é preciso considerar que a arte não reconhece fronteiras. Sua tendência é rompê-las. Sempre foi assim. A arte está acima das nações" (apud CABRAL, 2009, p. 57).

Arcádio Plazas clarifica que, mesmo sem a exata noção de proteção autoral, podemos verificar, já na legislação antiga, possibilidades de proteção ao direito de autor (apud, FIGUEIREDO, 2012, p.15).0 autor cita ainda o que diz Clóvis Beviláqua:

No Brasil, em 1827, pouco depois da independência, foram criados os cursos jurídicos. Em Olinda, surgiu a primeira notícia da proteção autoral. Nesta época, foi atribuído aos lentes da faculdade local o privilégio da exploração por dez anos daquilo que publicassem; logo depois, em 1830 o Código Penal do Império proibiu a reprodução de obras.

Após vários encontros mundiais, tais como: o congresso literário mundial presidido por Vitor Hugo, o congresso internacional de Bruxelas sobre obra literária (1858) e as conferências mundiais acerca do tema se tornaram cada vez mais claras.

Duas foram as principais convenções internacionais sobre propriedade intelectual. Em 1833, a de Paris, que dispõe sobre propriedade industrial, e, em 1886, a de Berna, que dispõe sobre direito de autor. Dessa conferência surgiu o mais 
importante texto normativo internacional sobre direito de autor (FIGUEIREDO, 2012, p. 16-17).

Decerto, a Convenção de Berna de 1886 foi o maior passo da humanidade em prol dos direitos de autor e, frise-se, é legislação internacional da qual o Brasil é signatário e está em pleno vigor.

Enfatiza ainda Fábio Vieira, que se podem assinalar, aqui, os principais pontos dessa convenção:

a) define como obra literária artística toda e qualquer produção no campo literário e artístico, qualquer que seja o modo ou a forma de expressão;

b) estabelece os critérios para proteção: o que se protege é a manifestação concreta do espírito criador;

c) define o que é obra publicada: "aquelas que foram editadas com o consentimento do autor qualquer que seja o modo de fabricação dos exemplares, sempre que a quantidade posta à disposição do público satisfaça razoavelmente suas necessidades";

d) declara que o gozo e exercício desses direitos não estarão subordinados a nenhuma formalidade, sendo, dessa forma, o autor identificado perante os tribunais pelo seu nome aposto à obra mesmo quando este for um pseudônimo;

e) fixa e define como país de origem aquele em que a obra fora publicada precipuamente;

f) assegura o direito de adaptação da obra, tradução autorizada, os direitos sobre obras dramáticas e dramático-musicais;

g) fixa o prazo de vigência dos direitos do autor em 50 anos após sua morte (a legislação brasileira alterou para 70 anos - era uma faculdade dos signatários); h) a convenção divide, claramente, os direitos de autor em patrimoniais e morais e torna os direitos morais irrenunciáveis, mesmo quando o autor dispõe do direito de exploração em favor de terceiros;

i) assegura o direito de paternidade da obra e também o de impedir modificações de qualquer natureza;

j) assegura por fim, o chamado droit de suíte, ou seja, a participação do autor nos lucros da eventual renda de sua obra (FIGUEIREDO, 2012, p. 17-18).

Em 1889, foi assinado acordo com Portugal que garante a proteção nacional aos 
autores portugueses e vice-versa. A matéria foi colocada na Constituição Brasileira já em 1891, no artigo 72, § 26, garantindo o direito exclusivo de reprodução:

Art. 72. A Constituição assegura a brasileiros e a estrangeiros residentes no País a inviolabilidade dos direitos concernentes à liberdade, à segurança individual e à propriedade, nos termos seguintes:

$\S 26$ - Aos autores de obras literárias e artísticas é garantido o direito exclusivo de reproduzi-las, pela imprensa ou por qualquer outro processo mecânico. Os herdeiros dos autores gozarão desse direito pelo tempo que a lei determinar. (FIGUEIREDO, 2012, p.18).

Fábio Vieira discorre, ainda, que o primeiro diploma legal específico foi promulgado em 1898; era a Lei $n^{\circ} 496$, o que deu força para que em 1916 o Código Civil desse título específico à matéria. Em 1973, foi promulgada a Lei Federal $\mathrm{n}^{\circ}$ 5.988/73, revogando os dispositivos específicos do Código Civil de 1916 que tratavam da matéria e que em 19 de fevereiro de 1998, foi promulgado o mais novo texto normativo brasileiro acerca dos direitos do autor, regulamentando e consolidando, ainda mais, os direitos constitucionais já ditados.

Além disso, na Constituição Federal, são ditadas as regras de proteção aos direitos do autor, sendo dessa forma, o direito de autor uma garantia constitucional.

No artigo $5^{\circ}$, XXVII e XXVIII, da Constituição Federal, o legislador constitucional salvaguardou os direitos do autor e, aqui, pede-se vênia para transcrever tais textos:

XXVII - (...) aos autores pertence o direito exclusivo de utilização, publicação ou reprodução de suas obras, transmissível aos herdeiros, pelo tempo que a lei fixar. XXVIII - são assegurados, nos termos da lei:

a) A proteçãoàs participações individuais em obras coletivas e à reprodução da imagem e voz humanas, inclusive nas atividades desportivas;

b) 0 direito de fiscalização e aproveitamento econômico das obras que criarem ou participarem aos criadores, aos intérpretes e às respectivas representações sindicais e associativas.

Com isso, se percebe, que o direito do autor, pelo sistema legal, ganha máxima importância, sendo ele, além de objeto de trabalho internacional, uma garantia constitucional. 
Fábio Vieira afirma por fim que, se tem ainda, a proteção do direito de autor no novo Código Civil - Dos Direitos da Personalidade, a saber:

Art. 11. Com exceção dos casos previstos em Lei, os direitos da personalidade são intransmissíveis e irrenunciáveis, não podendo o seu exercício sofrer limitação voluntária.

Parágrafo único. Em se tratando de morto, terá legitimação para requerer a medida prevista neste artigo o cônjuge sobrevivente, ou qualquer parente em linha reta, ou colateral até o quarto grau.

Art. 20. Salvo se autorizadas, ou se necessárias à administração da justiça ou à manutenção da ordem pública, a divulgação de escritos, a transmissão da palavra, ou a publicação, a exposição ou a utilização da imagem de uma pessoa poderão ser proibidas, a seu requerimento e sem prejuízo da indenização que couber, se the atingirem a honra, a boa fama ou a respeitabilidade, ou se se destinarem a fins comerciais.

Parágrafo único. Em se tratando de morto ou de ausente, são partes legítimas para requerer essa proteção o cônjuge, os ascendentes ou os descendentes. (VADE MECUM SARAIVA, 2006, p. 162-163).

A partir da visão de Fábio Vieira acerca do histórico quanto ao Direito de Autor, em que destaca fatos desde 1623 aos dias atuais, percebe-se o quanto o Direito de Autor ganhou, em termos de legislação, em favor da proteção dos direitos da obra criada, delegando segurança e benefícios aos autores de gozar dos privilégios de suas obras, tal qual destaca o Direito da Personalidade garantido no Código Civil/2002.

Como citado no início deste capítulo, mesmo com a legislação vigente, há uma grande lacuna no que tange ao reconhecimento do direito de autor no Brasil. Muitas vezes pelo desconhecimento do autor da obra quanto aos benefícios que esta legislação lhes confere, causando desta forma um total descontrole destes benefícios, ficando em sua maioria o reconhecimento, os direitos e as benesses em favor de terceiros interessados em usurpar os diretos dos autores de fato.

\subsubsection{O Direito Autoral nos Tratados e Convenções Internacionais}

Segundo Manuella Santos, em 1858 em Bruxelas, realizou-se o primeiro con- 
gresso internacional sobre propriedade intelectual. Contou com a participação oficial e não oficial de vários países, além de escritores, cientistas e jornalistas. Embora não tenha tido consequências imediatas, esse evento lançou as sementes para a apreciação internacional dos direitos de autor. Manuella Santos destaca ainda que:

Em 1878 o escritor Victor Hugo presidiu o Congresso Literário Artístico Internacional, órgão que passou a trabalhar em prol da defesa dos direitos universais do autor. Nesse encontro preconizou-se a adoção de leis uniformes para a proteção dos direitos de autor, diante da existência, à época, de inúmeros acordos internacionais bilaterais, alguns dos quais contendo a cláusula de nação mais favorecida, o que obrigava o jurista à exaustiva pesquisa para definir os contornos da proteção mais adequada.

Em 1883, em Paris, ocorreu a primeira convenção internacional sobre a propriedade industrial.

Em 1886, sob os auspícios do Governo Suíço, realizou-se na cidade de Berna uma importante reunião em que foram discutidos e aprovados os princípios básicos que resultaram na elaboração e assinatura de um instrumento com vinte e um artigos (e um adicional), convencido como Convenção de Berna.

Nesse encontro que se tornou o grande marco internacional do direito de autor, as nações participantes estabeleceram diretrizes de aplicação das normas autorais em seus ordenamentos jurídicos, comprometendo-se a refletir, em suas legislações nacionais, as garantias de proteção aos autores ali pactuadas.

Assim a convenção de Berna consagrou de forma ampla e definitiva os direitos de autor em todo o mundo. Em vigência desde 5 de dezembro de 1887, foi objeto de dois aditamentos e cinco revisões. Os aditamentos ocorreram em 1896 (em Paris) e 1914 (em Berna). As revisões se deram em 1908 (em Berlim), em 1928 (em Roma), em 1948 (em Bruxelas), em 1967 (em Estocolmo) e em 1971 (em Paris). Além disso, houve ainda uma modificação em 1979 (em Paris) (SANTOS, 2009, p. 6061).

Fábio Vieira Figueiredo destaca que não há como tratar da proteção ao direito de autor, no âmbito internacional, sem mencionar a Convenção de Berna.

A convenção é, sem qualquer sombra de dúvidas, o precípuo instrumento in- 
ternacional para a proteção do direito de autor, eis que foi ratificada por mais de cem países. Foi aprovada em 9-9-1886 e atualizada ou complementada em outras tantas oportunidades (4-5-1896, 13-11-1908, 20-3-1914, 2-6-1928, 266-1948, 14-7-1967 e 28-9-1979). Foi, portanto, completada em Paris em 4 de maio de 1896, revista em Berlim em 13 de novembro de 1908, completada em Berna em 20 de março de 1914 e revista em Roma em 2 de junho de 1928, em Bruxelas em 26 de junho de 1948, em Estocolmo em 14 de julho de 1967 e em Paris em 24 de julho de 1971. O texto foi, por fim atualizado em setembro de 1979. Atualmente a convenção é administrada pela OMPI (Organização Mundial da Propriedade Intelectual) e estabelece alguns princípios básicos: 1) princípio do tratamento nacional; 2) princípio da garantia dos mínimos convencionais; 3) princípio da determinação do país de origem da obra; 4) princípio da conformidade da legislação interna. Desse modo cumpre ainda ressaltar que a Convenção de Berna, na proteção dos direitos do autor, resguarda de maneira expressa e ampla a fração extrapatrimonial de referido direito. 0 artigo 6-BIS da Convenção dispõe:

Artigo 6-BIS: 1) Independentemente dos direitos patrimoniais de autor, e mesmo após a cessão dos referidos direitos, o autor conserva o direito de reivindicar a paternidade da obra e de se opor a qualquer deformação, mutilação ou outra modificação da obra ou a qualquer outro atentado contra a mesma obra, prejudicial à sua honra ou à sua reputação. (FIGUEIREDO, 2012, p. 147-149).

Em análise ao pensamento dos autores, tanto Manuella Santos quanto Fábio Vieira Figueiredo enfatizam a Convenção de Berna como um marco essencial na proteção do autor quanto as suas obras, tornando-se um instrumento internacional, consagrando em todo mundo de forma ampla e definitiva o direito de autor, tendo o compromisso dos países presentes a fazerem uma reflexão acerca da legislação de seus respectivos países para o cumprimento do que fora ali pactuado.

Ainda Manuella Santos destaca que, logo após a Convenção de Berna começou um esforço em prol dos direitos autorais no continente americano, inaugurado pelo Congresso de Direito Internacional Privado de Montividéu, em 1889. A fim de ilustrar esse momento a autora transcreve abaixo:

No início do século XIX, numerosos estados, designadamente da América Latina, tinham já adoptado uma legislação nacional sobre o direito de autor, 
modificando-a de quando em vez a fim de a adaptar às necessidades das novas tecnologias. Todavia, essa legislação era relativamente fragmentária e o caráter territorial das leis sobre o direito de autor mantinha-se inalterado. A proteção concedida pelas leis nacionais só e, em princípio, aplicável em território nacional. Ora, o desenvolvimento das relações internacionais, as trocas culturais, a tradução de obras noutras línguas tornavam necessário assegurar a proteção das obras de origem nacional fora do território nacional e dos autores estrangeiros dentro das fronteiras do país. Historicamente, a proteção inicialmente concedida às obras estrangeiras deveu-se à inserção nas leis nacionais de cláusulas especiais de reciprocidade (SANTOS, 2009, p. 61-62).

Segundo Carlos Alberto Bittar, além disso, houve a Convenção Universal de Genebra (da UNESCO, de 06.09.1952), revista em Paris (1971). Outras convenções foram, ainda, realizadas, como a de direitos conexos, de Roma (26.10.1961) e a de Genebra (29.10.1971). O acordo TRIPS inova nas leis do Comércio Internacional.

Ainda para Bittar, no continente americano, o primeiro esforço deu-se no Congresso de Direito Internacional Privado de Montevidéu (11.02.1889), revisto na mesma cidade $(04.08 .1939)$. Outras convenções foram realizadas no México (27.01.1902), no Rio de Janeiro (23.08.1906), em Buenos Aires (11.08.1910), em Caracas (17.07.1911, regional), em Havana (18.02.1928, para revisão da de Buenos Aires) e em Washington (22.06.1946), que substituiu as demais). 0 autor destaca ainda:

O Brasil aprovou, em seu Direito interno, vários textos das convenções internacionais citadas, dentre as quais, as de Berlim (Decreto 15.330, de 21.06.1922), Roma (Decreto 23.270, de 24.10.1933), Bruxelas (Decreto 34.954, de 18.01.1954), Roma (Decreto 57.125, de 19.10.1965, de direitos conexos)) e Paris (Decreto 79.905, de 24.12.1975), além das de Genebra (Decreto 48.458, de 04.07.1960), Convenção Universal, revisão de Paris (Decreto 76.905, de 24.12.1975, e Decreto 76.906, de 24.12.1975, de direitos conexos), e interamericanas, do Rio de Janeiro (Decreto 9.190, de 06.12.1911), Buenos Aires (Decreto 11.588, de 19.05.1915) e Washington (Decreto 26.675, de 18.05.1949). Aderiu, ainda, a outras convenções, como a que instituiu a Organização Mundial da Propriedade Intelectual (OMPI), de Paris, de 14.07.1971 (Decreto 75.541, de 32.05.1975), e a sobre sinais emitidos por satélites de comunicação de Bruxe- 
las, de 21.05.1974 (Decreto 74.130, de 28.05.1974) (BITTAR, 1939-1997-2013, p. 32).

$\mathrm{Na}$ visão de Bittar, o Direito de Autor é disciplinado no plano nacional e internacional em constituições e em leis ordinárias, como também nas convenções foram firmados princípios e orientações que imprimem certa uniformização à legislação interna dos países participantes.

\subsubsection{Escorço Histórico-Legislativo no Brasil}

Segundo Manuella Santos, a história do Direito de Autor no Brasil data de 1898. A autora destaca o que Elisângela Dias Menezes frisa que, durante o período colonial a imprensa era proibida e não havia qualquer estímulo à evolução do sistema de impressão gráfica. A Legislação submetia-se ao ordenamento jurídico português, cuja Constituição, de 1838, apenas garantia, mas não especificava, os direitos dos escritores sobre seus textos. E cita ainda que:

Mesmo após a independência, o regime imperial ainda usava o antigo sistema de privilégio, para definir a exclusividade de exploração econômica das obras. Assim como ocorria na Europa, somente os editores e impressores tinham direitos sobre as obras e, do mesmo modo, mediante outorga política de prerrogativas (SANTOS, 2009, p.43).

Analisando o tema, Manuella Santos cita que Antônio Chaves divide a história do Direito autoral no Brasil em três fases: de 1827 a 1916, de 1916 a 1973, e de 1973 até os dias atuais. Essa divisão tem por base as normas que se tornaram marcos para a matéria em nosso País: em 1827 foi publicado o primeiro diploma legal a fazer referência ao direito de autor; em 1916 foi promulgado o Código Civil e, em 1973, foi publicada a antiga Lei de direitos autorais (SANTOS, 2009, p.43).

\subsubsection{Primeiros diplomas legais}

Manuella Santos destaca que a grande dificuldade da propriedade intelectual no Brasil não reside na falta de previsão legal, mas no cumprimento dos diplomas 
existentes. Em 1827 foi publicada no Brasil a lei que instituiu os cursos jurídicos de Olinda e São Paulo, que trazia a seguinte disposição em ser art. $7^{\circ}$ :

Art. $7^{\circ}$. - Os lentes farão a escolha dos compêndios da sua profissão, ou os arranjarão, não existindo já feito, contanto que as doutrinas estejam de acordo com o sistema jurado pela nação. Esses compêndios, depois de aprovados pela Congregação, servirão interinamente, submetendo-se, porém à aprovação da Assembleia Geral, e o governo fará imprimir e fornecer às escolas, competindo aos seus autores o privilégio exclusivo da obra por dez anos (SANTOS, 2009, p.44).

Eduardo Vieira Manso, apud Manuella Santos, explica que por meio dessa lei os mestres nomeados deveriam encaminhar às Assembleias Gerais os seus compêndios das matérias que lecionavam a fim de receber ou não a aprovação. Se recebessem a aprovação gozariam, também, do privilégio de publicação por dez anos. Tratava-se, assim, de uma norma aplicável apenas intra muros, nas Faculdades de Direito de Olinda e São Paulo, não alcançando os demais autores (SANTOS, 2009, p. 45).

Em 1830 o aspecto moral foi reconhecido pelo Código Criminal do Império, que trouxe a seguinte previsão no art. 261:

Art. 261 - Imprimir, gravar, litografar ou introduzir quaisquer escritos ou estampas, que tiverem sido feitos, compostos ou traduzidos por cidadãos brasileiros, enquanto estes viverem, e dez anos depois de sua morte se deixarem herdeiros.

Penas - Perda de todos os exemplares para o autor ou tradutor, ou seus herdeiros, ou, na falta deles, do seu valor e outro tanto, e de multa igual ao dobro do valor dos exemplares. Se os escritos ou estampas pertencerem a corporações, a proibição de imprimir, gravar, litografar ou introduzir durará somente por espaço de dez anos.

Observa-se, neste caso, que a primeira regulação dos direitos autorais no Brasil é feita pela legislação penal e não pela civil.

\subsubsection{Proteção Infraconstitucional}

Segundo Manuella Santos, a primeira legislação infraconstitucional a regulamentar efetivamente o direito autoral no Brasil foi a Lei n. 496, de $1^{\circ}$. de agosto 
de 1898, de autoria do Deputado Medeiros e Albuquerque. Essa lei era composta por vinte e sete artigos e trazia a seguinte ementa: "define e garante os direitos autorais". Seu art. $1^{\circ}$. era bastante esclarecedor:

Art. $1^{\circ}$. - Os direitos de autor de qualquer obra literária, científica ou artística consistem na faculdade, que só ele tem, de reproduzir ou autorizar a reprodução do seu trabalho pela publicação, tradução, representação, execução ou de qualquer outro modo.

A lei garante estes direitos aos nacionaes e estrangeiros residentes no Brazil, nos termos do art. 72 da Constituição, si os autores preencherem as condições do art. 13 (SANTOS, 2009, p.52).

Nota-se, neste caso, que a proteção visava às obras nacionais e as obras de brasileiros e estrangeiros residentes no Brasil.

Em 17 de janeiro de 1912 foi publicada a Lei n. 2.577, estendendo a proteção da Lei n. 496 às obras editadas em países estrangeiros, qualquer que fosse a nacionalidade de seus autores, desde que eles pertencessem a nações que tivessem aderido às convenções internacionais sobre a matéria, ou que tivessem assinado tratados com o Brasil, assegurando a reciprocidade no tratamento às obras brasileiras.

Art. $1^{\circ}$. - Todas as disposições da Lei n. 496, de 1 de agosto de 1898, salvo as do seu art. 13, são igualmente applicaveis ás obras scientificas, literarias e artisticas, editadas em paizes estrangeiros, qualquer que seja a nacionalidade de seus autores, desde que elles pertençam a nações que tenham adherido ás convenções internacionaes sobre a materia, ou tenham assignado tratados com o Brazil, assegurando a reciprocidade do tratamento ás obras brasileiras.

Art. $2^{\circ}$. Para gozar da proteção concedida por esta lei basta ao autor da obra estrangeira, provar que preencheu todas as formalidades exigidas para garantia dos direitos de autor, pela legislação do paiz em que ella foi pela primeira vez publicada (SANTOS, 2009, p.53).

Esta lei se revelou de grande importância para os autores estrangeiros, lhes assegurando o direito de autor, em um tempo em que no Brasil muitas obras estrangeiras eram copiadas indiscriminadamente. 
Ainda para Manuella Santos, quatro anos depois foi promulgado o Código Civil de 1916, revogando a Lei n. 496. Esse diploma foi um marco para a matéria ao regular o assunto nos artigos 649 a 673, sob a epígrafe “da propriedade literária, científica e artística".

Em 1973 foi promulgada a Lei n. 5.988, derrogando por completo os artigos 649 a 673 do Código Civil. Em 1975 o Decreto n. 75.699 ratificou a Convenção de Berna no Brasil, ajustando em definitivo a estrutura jurídica nacional com as diretrizes internacionais. No mesmo ano, o decreto n. 76.905 ratificou a revisão ocorrida em 1971, em Paris, sobre a referida convenção (SANTOS, 2009, p.54).

Em 1998 foi promulgada a Lei n. 9.610, de 19 de fevereiro, que altera, atualiza e consolida a legislação sobre direitos autorais e dá outras providências, a atual lei de direitos autorais vigente no Brasil.

Analisando a legislação até então existente no Brasil, a Lei 9.610 denomina-se como a mais abrangente no que concerne ao aspecto aos direitos de autor, garantindo-lhes a proteção assegurada nos acordos internacionais.

A partir da publicação da Lei n. 12. 853, de 14 de agosto de 2013, houve alterações na Lei 9.610, que define:

Art. $1^{\circ}$. Esta Lei dispõe sobre a gestão coletiva de direitos autorais, altera, revoga e acrescenta dispositivos à Lei n. 9.610, de 19 de fevereiro de 1998.

Art. $2^{\circ}$. Os arts. $5^{\circ}$., 68, 97, 98, 99 e 100 da Lei n. 9.610, de 19 de fevereiro de fevereiro de 1998, passam a vigorar com as seguintes alterações:

“Art. $5^{\circ}$. XIV - titular originário - o autor de obra intelectual, o intérprete, o executante, o produtor fonográfico e as empresas de radiodifusão." (...)

Art. $3^{\circ}$. A Lei n. 9.610, de 1998, passa a vigorar acrescida dos seguintes arts. 98-

A, 98-B, 98-C, 99-A, 99-B, 100-A, 100-B e 109-A. (...) (CÂMARA DOS DEPUTADOS, Lei 12.853, 23 jul. 2014).

Esta Lei n. 12.853, altera e acrescenta a Lei n. 9.610, essencialmente à normatização sobre a gestão coletiva de Associações de direitos autorais, com o intuito de garantir aos associados o acesso às informações referentes às obras sobre as quais sejam titulares de direitos. 


\subsection{Direito de Autor}

\subsubsection{O Direito de Autor: conceituação}

Para Bittar, o Direito de Autor ou Direito Autoral é o ramo do Direito Privado que regula as relações jurídicas, advindas da criação e da utilização econômica de obras intelectuais estéticas e compreendidas na literatura, nas artes e nas ciências (BITTAR, 2013, p.27).

Como Direito subjetivista e privatista, recebeu consagração legislativa em função da doutrina dos direitos individuais no século XVIII. Neste contexto, Bittar destaca ainda que:

Depende do jus naturalismo liberal e do desenvolvimento da doutrina dos direitos fundamentais da pessoa humana. Inspirado por noções de defesa do homem enquanto criador, em suas relações com os frutos de seu intelecto, inscreve-se no âmbito do Direito Privado embora entrecortado por normas de ordem pública exatamente para a obtenção de suas finalidades. Seu sentido mais atual impõe, cada vez mais, sua atualização diante das inovações tecnológicas e dos desafios do uso compartilhado do conhecimento.

As relações regidas por esse Direito nascem com a criação da obra, exsurgindo, do próprio ato criador, direitos respeitantes à sua face pessoal (como os direitos de paternidade, de nominação, de integridade da obra) e, de outro lado, com sua comunicação ao público, os direitos patrimoniais (distribuídos por dois grupos de processos, a saber, os de representação e os de reprodução da obra, por exemplo, para as músicas, os direitos de fixação gráfica, de gravação, de inserção em fita, de inserção em filme, de execução e outros).

As obras protegidas são as destinadas à sensibilização ou à transmissão de conhecimentos, a saber, as obras de caráter estético, que se inscrevem na literatura (escrito, poema, romance, conto), nas artes (pintura, escultura, projeto de arquitetura, filme cinematográfico, fotografia) ou nas ciências (relato, tese, descrição de pesquisa, demonstração escrita, bula medicinal) (BITTAR, 2013, p. 27).

O autor contextualiza de forma tão clara as noções das defesas do homem enquanto criador e enfoca quão importante são as relações regidas por esse direito com a criação da obra e seus direitos respeitantes à sua face pessoal. 


\subsubsection{Regimes Legislativos sobre os Direitos}

Segundo Bittar, em especial por forças de influências culturais e políticas, os regimes legislativos sobre direitos autorais podem se dividir em três grandes sistemas: o individual, o comercial e o coletivo. São eles:

O sistema individual (europeu ou francês) é o da Convenção de Berna, de caráter subjetivo, dirigido à proteção do autor e consubstanciado na exclusividade que se lhe outorga, permitindo-lhe a participação em todos os diversos meios de utilização econômica. Corolários deste regime são: o do alcance limitado das convenções celebradas pelo autor para a exploração da obra e da interpretação estrita dessas convenções, em defesa dos interesses do criador. A proteção é conferida independentemente de registro da obra ou outra formalidade.

O sistema comercial é o desenvolvimento nos Estados Unidos e na Inglaterra (e países que sofreram sua influência), relacionando-se com a proteção da cultura do país; daí por que se volta para a obra em si, em posição objetiva. 0 copyright é concedido ao titular, mas para efeito de expansão da cultura e da ciência, exigindo-se formalidades para o gozo da exclusividade, conforme, inclusive, definido no contexto da Convenção de Genebra (1952).

O sistema coletivo era o da Rússia e dos países sob a égide, em que a proteção dos direitos se considerava elemento essencial para a expansão da cultura. A visão coletiva preponderava sobre a visão subjetivista. O Direito era reconhecido para o alcance do progresso do socialismo, ficando o respectivo regime jurídico sujeito à esquematização baseada na Convenção de Berna (BITTAR, 2013, p. 28).

Nos sistemas legislativos ora em destaque, observa-se que no sistema individual, o da Convenção de Berna permite ao autor da obra a participação em todos os diversos meios de utilização econômica, no sistema comercial, o copyrighté concedido ao titular, exigindo formalidade para o gozo da exclusividade, definido na Convenção de Genebra e no sistema coletivo, considera a proteção dos direitos, elemento essencial para a expansão da cultura, também baseado na Convenção de Berna. Ao fazer uma analogia com o que acontece usualmente no Brasil, observa-se total disparidade, daí a necessidade de disseminar os benefícios e privilégios do direito de autor, em busca do reconhecimento e proteção para os autores de nossas obras. 


\subsubsection{Denominações}

Diferentes denominações receberam ao longo dos tempos desta Bittar, em função da evolução experimentada ou em relação à posição doutrinária de seu defensor, desde a expressão "propriedade literária, artística e científica", com que ingressou no cenário jurídico, a saber: "propriedade imaterial”, "direitos intelectuais sobre as obras literárias e artísticas", "direitos imateriais", "direitos sobre bens imateriais", "direitos de criação" e, mais recentemente, "Direito Autoral", "Direitos de Autor" e "Direito de Autor". Fala-se, ainda, em "autoralismo". Bittar contextualiza ainda que:

Observa-se, atualmente, a preferência pelo nome "Direito de Autor", na doutrina, na jurisprudência e na legislação. As obras mais modernas já ostentam essa denominação, que os autores utilizam, aliás, indistintamente, ao lado da expressão “Direito Autoral”(neologismo introduzido por Tobias Barreto, em 1882).

Diante da diversidade de denominações, observa-se que o mais usual atualmente denomina-se "Direito de Autor", por traduzir de forma clara o real significado de que trata o assunto de autoria de uma determinada obra, independente do tipo de obra, se literária, artística ou científica (BITTAR, 2013, p.28-29).

Ao analisar as diferentes denominações de Direito de Autor citadas por Bittar, observa-se que há dificuldade de entendimento até para os estudiosos deste assunto, dificuldade esta que se reflete na busca de informações efetivas pelos autores na forma de resguardar os benefícios de suas obras.

\subsubsection{Natureza}

Várias teorias foram oferecidas para explicar a natureza do Direito de autor, em função do estágio de evolução em que se encontravam a matéria e a posição doutrinária de seu defensor, ora considerando-o como privilégio para incremento das letras e das artes, ora definindo-o como Direito de Propriedade, ora qualificando-o como Direito da Personalidade, além de inúmeras variações, combinações e certas posições singulares. Na visão de Bittar:

No entanto, em face de diferentes fatores e de elementos estruturais pró- 
prios, vem o Direito de Autor sendo considerado como um Direito Especial, sui generis, que não se insere dentro das colocações assinaladas, mas, ao revés, reclama a sua consideração como Direito Autônomo.Com efeito, detendo-nos nas principais posições sustentadas, temos de início, que a consideração como direito de Propriedade está ligada ao próprio reconhecimento desse Direito e às dificuldades iniciais de categorização diversa, diante da então intangibilidade da classificação romana, que, aliás, embasou todo trabalho de codificação. Como se tratava de direito sobre coisa incorpórea, sua introdução no sistema codificado deu-se pela via dos direitos reais, como direito de Propriedade imaterial. Entretanto, com isso, ganhou foros de Direito o então privilégio e, ademais, reconhecido ao autor da obra, a partir da observação de que a criação é o título atributivo dessa qualificação (BITTAR, 2013, p. 29).

Em análise acerca da visão de Bittar, entende-se que, o privilégio conquistado pelo Direito autoral em face de diferentes fatores e de elementos estruturais próprios, ora sendo considerado como privilégio para incremento das letras e das artes, ora como Direito de Propriedade e ora qualificando-se como Direito de Personalidade, o destacou em sua evolução como um Direito Especial, reconhecido ao autor da obra, mais uma vez, garantindo-lhes a proteção de suas criações, que é o título atributivo dessa qualificação.

\subsubsection{Características básicas}

Segundo Bittar, o Direito de Autor, em consequência, é Direito especial, sujeito a disciplinação própria, apartada das codificações, perante princípios e regras consagradas, universalmente, em sua esquematização estrutural.

Com efeito, análise de sua conformação intrínseca demonstra, desde logo, a individualidade lógica e formal do Direito de Autor, na medida em que se reveste de características próprias, identificáveis na doutrina, na jurisprudência e na legislação, nacional e internacional. Bittar destaca ainda, que:

Adentrando-se em sua ossatura, percebe-se de fato, que se destacam certas particularidades, que o distinguem dos demais direitos privados e se acham cristalizados no complexo normativo desse Direito, a saber: a) dualidade de aspectos em sua cunhagem, que, embora separáveis para efeito de circulação 
jurídica, são incindíveis por natureza e por definição; b) perenidade e inalienabilidade dos direitos decorrentes do vínculo pessoal do autor com a obra, de que decorre a impossibilidade de transferência plena a terceiros, mesmo que o queira o criador; c) limitação dos direitos de cunho patrimonial; d) exclusividade do autor, pelo prazo definido em lei, para a exploração econômica da obra; e) integração, a seu contexto de cada processo autônomo de comunicação da obra, correspondendo cada qual a um Direito Patrimonial; f) limitabilidade dos negócios jurídicos celebrados para utilização econômica da obra; g) interpretação estrita das convenções firmadas pelo autor; h) licença não voluntária pelo interesse de acesso à cultura depositado na obra (BITTAR, 2013, p. 30).

Ao analisar a contextualização de Bittar, em destaque para as premissas básicas que disciplinam o Direito de Autor como um direito especial, com regras já consagradas na esfera nacional e internacional, se percebe que de fato há certas particularidades que o distinguem dos demais direitos privados, essencialmente ao analisar os complexos normativos desse direito. Vale ressaltar a importância destes complexos normativos, como características essenciais para a garantia dos autores diante de suas obras.

\section{Os Direitos Morais do Autor}

Segundo Manuella Santos, o direito moral de autor prevalece sobre o patrimonial, e isso decorre do fato de ser a primeira modalidade de direito da personalidade. Por consequência, a obra intelectual, como criação do espírito, vincula-se à personalidade do autor. Por isso se diz que o autor "vive" em sua obra.

A autora destaca ainda, que os direitos morais do autor são aqueles que unem indissoluvelmente o criador à obra criada. É uma prerrogativa de caráter pessoal, é um direito personalíssimo. 0 art. 24 da LDA elenca os direitos morais do autor:

Art. 24. São direitos morais do autor:

I - o de reivindicar, a qualquer tempo, a autoria da obra;

II - o de ter seu nome, pseudônimo ou sinal convencional indicado ou anuncia-

do, como sendo o do autor, na utilização de sua obra;

III - o de conservar a obra inédita;

IV - o de assegurar a integridade da obra, opondo-se a quaisquer modificações 
ou a prática de atos que, de qualquer forma, possam prejudicá-la ou atingi-lo, como autor, em sua reputação de honra;

V - o de modificar a obra, antes ou depois de utilizada;

VI - o de retirar de circulação a obra ou de suspender qualquer forma de utilização já autorizada, quando a circulação ou utilização implicarem afronta à sua reputação e imagem;

VII - o de ter acesso a exemplar único e raro da obra, quando se encontre legitimamente em poder de outrem, para o fim de, por meio de processo fotográfico ou assemelhado, ou audiovisual, preservar sua memória, de forma que cause o menor inconveniente possível a seu detentor, que, em todo caso, será indenizado de qualquer dano ou prejuízo que the seja causado (SANTOS, 2009, p. 81-82).

Ainda para Manuella Santos, esse dispositivo é complementado pelo artigo 27, que dispõe que os direitos morais do autor são inalienáveis e irrenunciáveis. A leitura do dispositivo reitera o entendimento de que o direito moral, pessoal ou intelectual é direito da personalidade e como tal goza dos seguintes atributos:

Oponibilidade erga omnes, indisponibilidade, incomunicabilidade, impenhorabilidade e imprescritibilidade.

Assim, o autor é titular de direitos morais, como a paternidade da obra, a integridade, o direito de conservar a obra inédita, o direito de arrependimento ou direito de retrato que, no dizer de Eduardo Vieira Manso, autoriza o autor a retirar sua obra de circulação, bem como de suspender-lhe qualquer forma de utilização já iniciada ou simplesmente autorizada, desde que responda pelos danos que sua decisão causar a terceiros (SANTOS, 2009, p. 83).

Nesta análise ao pensamento dos autores acima citados, destaca-se que Bittar enfatiza o aspecto geral dos direitos morais, como vínculos perenes, que unem o autor à obra. Já Manuella Santos, dá ênfase às especificidades ao destacar que o direito moral de autor prevalece sobre o patrimonial e isso decorre do fato de ser a primeira modalidade de direito da personalidade.

Carlos Alberto Bittar destaca que as características desses direitos são: a personalidade; a perpetuidade; a inalienabilidade; a imprescritibilidade; e a impenhorabilidade. Destaca também que: 
De início, são direitos de natureza pessoal, cabível a ideia para as pessoas jurídicas, inserindo-se nessa categoria direitos de ordem personalíssima; são também perpétuos ou perenes, não se extinguindo-se jamais; são inalienáveis, não podendo, pois, ingressar legitimamente no comércio jurídico, mesmo se o quiser o criador, pois deles não pode dispor; são imprescritíveis, comportando, pois, exigência por via judicial a qualquer tempo; e, por fim, são impenhoráveis, não suportando, pois constrição judicial (a lei fala em inalienabilidade e irrenunciabilidade, art. 27, realçando, em outro passo, a inacessibilidade dos direitos - art. 49, inciso I) (BITTAR, 2013, p. 69).

Segundo Bittar observa-se, pois, com a rígida qualificação dos direitos em causa, que, por toda a vida, a marca pessoal do autor acompanha a sua criação, persistindo ad aeternitatem com a sua morte, e mesmo depois de esgotada a exclusividade patrimonial, ou sofrida adaptação para outro gênero (que, por si, não afeta o direito moral, eis que importa em adoção de forma outra, com linguagem própria e concretizada em obra independente, como é o caso do direito conexo) (BITTAR, 2013, p. 69-70).

Em análise do que enfatiza Bittar, acerca das características dos direitos morais de autor, observa-se que a marca pessoal do autor acompanha a sua criação por toda vida, garantindo-lhe os benefícios que lhe é direito a partir da sua criação, persistindo ad aeternitatem.

Ademais, com o intuito de complementar o embasamento deste estudo, busca-se em decisões do STF matéria julgada que comtempla em sua decisão o destaque para os direitos morais do autor.

\subsection{Amostra de decisão de Direitos Morais de autor}

O exemplo abaixo retrata a realidade de que trata a Lei de Direitos Autorais e em especial os direitos morais de autor, ao demonstrar um caso, onde a Editora ao publicar a matéria jornalística "O conto dos quilombos" na revista "ISTO É" (fl. 44), deixou de indicar a fonte e autoria do mapa que ilustra a reportagem.

Destaca-se o caso em questão:

Em 04 de maio de 2011 foi votado o Acórdão Certificado n.: 7143 2B F2 00 05000010 2A, publicada em 10.05.2011 - 16:26, onde acordam os Senhores 
Desembargadores da $2^{\mathrm{a}}$. Turma Cível do Tribunal de Justiça do Distrito Federal e dos Territórios, WALDIR LEÔNCIO LOPES JÚNIOR - Relator, J.J. COSTA CARVALHO - Revisor, CARMELITA BRASIL - Vogal, sob a Presidência do Senhor Desembargador WALDIR LEÔNCIO LOPES JÚNIOR, em proferir a seguinte decisão: DAR PARCIAL PROVIMENTO. UNÂNIME, de acordo com a ata do julgamento de notas taquigráficas.

Nesse sentido:

DIREITO AUTORAL. OBRAS FOTOGRÁFICAS PUBLICADAS SEM INDICAÇÃO DE AUTORIA. DANO MORAL. EXTENSÃO DO CONSENTIMENTO DO AUTOR DA OBRA. REEXAME DE PROVAS. INCIDÊNCIA DA SÚMULA 07.

(...)

4. A simples circunstância de as fotografias terem sido publicadas sem a indicação de autoria - como restou incontroverso nos autos - é o bastante para render ensejo à reprimenda indenizatória por danos morais.

5. O valor da condenação por danos morais ( $R \$ 15.000,00)$ deve ser mantido, uma vez não se distanciar dos parâmetros praticados por esta Corte.

6. Recurso especial não conhecido. (REspNo 750.822 - RS, Rel. Min. Luis Felipe Salomão, 4 $4^{\mathrm{a}}$ Turma, julgado em 09/02/2010, DJ 01/03/2010)

CIVIL E PROCESSO CIVIL. AÇÃO INDENIZATÓRIA PELO USO INDEVIDO DE FOTOGRAFIA. DANOS MORAIS. DIREITOS AUTORAIS. INTERNET. USO DA OBRA SEM O CONSENTIMENTO DO AUTOR E SEM A DEVIDA INDICAÇÃO DE AUTORIA. IMPOSSIBILIDADE.

1 - A publicação de fotografia sem o consentimento do autor e sem a correta indicação da autoria da obra, enseja o direito à indenização por danos morais. Precedentes do STJ.

2 - Recurso não provido. (20070111316088APC, Rel. Cruz Macedo, 4 $4^{\mathrm{a}}$ Turma Cível, julgado em 18/02/2009, DJ 23/03/2009, p. 102)

\section{Os Direitos Patrimoniais do Autor}

Os direitos patrimoniais do autor são direitos pecuniários exclusivos do criador, decorrentes da exploração econômica da obra, conforme se depreende da leitura do artigo 28 da Lei do Direito Autoral: "Cabe ao autor o direito exclusivo de utilizar, fruir e dispor da obra literária, artística ou científica”.

Segundo Manuella Santos, a exploração econômica da obra intelectual cons- 
titui verdadeiro monopólio do autor, fazendo-se imprescindível a sua autorização prévia a fim de que alguma pessoa possa vir a fruir rendimentos pela utilização da criação estética. Desse modo, os direitos patrimoniais do autor apresentam as seguintes características: transmissibilidade, temporariedade, prescritibilidade e disponibilidade (SANTOS, 2009, p. 84).

Nesta análise, a referida autora destaca que os direitos patrimoniais têm aspectos específicos por serem direitos exclusivos do criador e que dependem de prévia e expressa autorização do autor ou de quem o represente, para que possam ser reproduzidos, exibidos, expostos publicamente, transmitidos por meios digitais e demais formas de exposição da obra.

Bittar destaca que esses direitos estão por sua natureza, relacionados, intrinsecamente, com os meios de comunicação, especialmente diante de seus rápidos e imutáveis movimentos com os quais se concretizam na prática, de sorte que a cada processo autônomo de utilização corresponde uma prerrogativa patrimonial. Bittar destaca ainda que:

Entende-se, pois, existente o direito em cada fase acabada de colocação da obra em contato com o público (uma melodia pode ser editada em partitura gravada inserida em disco ou fita executada em rádio, captada e difundida em alto-falante, ou captada em aparelho em quarto de hotel), representando cada qual desses usos um direito patrimonial.

Ora, como a comunicação pode se fazer diretamente (sob forma incorpórea ou imaterial), ou indiretamente (sob forma corpórea ou material), englobando meios os mais diferentes (cinema, televisão, radar, satélite e outros tantos), resumem-se, globalmente, nos direitos de representação e de reprodução da obra (BITTAR, p.72).

Ao analisar o pensamento de Bittar acerca destas características dos Direitos patrimoniais de autor, observa-se quão vasta é a possibilidade de ganho pecuniário do autor sobre sua obra, principalmente diante da diversidade de meios de comunicação existentes hoje, o que reforça ainda mais a atenção dos autores e seus representantes para a fiscalização visando o ganho real de seus direitos garantidos por lei a partir da utilização de suas obras. 


\subsection{Amostra de decisão de Direitos Patrimoniais de autor}

O Exemplo citado abaixo se trata de Ação de Indenização por Danos Morais e Materiais, proposta por DALMI RODRIGUES DE MORAIS em desfavor da COMPANHIA IMOBILIÁRIA DE BRASÍLIA - TERRACAP, alegando, em suma, que houve a utilização irregular e desautorizada de material fotográfico produzido pelo mesmo. Onde o autor afirma que houve a contratação para utilização uma única vez da foto produzida, porém a Ré continuou a utilizar as fotos sem autorização e com alteração do formato. Entende-se neste caso, que a Ré deveria renovar o contrato com o autor para utilizar a foto de sua autoria por um novo período, pagando-lhe o que lhe é de direito.

Destaca-se o caso em questão:

EMENTA. PROCESSUAL CIVIL - AÇÃO DE INDENIZAÇÃO - DIREITO AUTORAL TERRACAP - COISA JULGADA - VIOLAÇÃO - PROCESSO EXTINTO SEM RESOLUÇÃO DO MÉRITO - ÔNUS DA SUCUMBÊNCIA - EXIGIBILIDADE DA CONDENAÇÃO SUSPENSA - ART. 12 DA LEI N¹1.060/50 - SENTENÇA PARCIALMENTE REFORMADA. 1. Na hipótese, o autor renova o pedido de indenização por violação de direito autoral, deduzido em face da Terracap, em que pese ter sido rejeitado por sentença transitada em julgado em ação indenizatória anterior, o que autoriza a extinção do segundo processo por respeito à coisa julgada (art. 267, inc. V, do (PC).

2. O fato de ser beneficiário da justiça gratuita não isenta o autor do pagamento das custas processuais e dos honorários advocatícios, como consectário da sucumbência experimentada. A Lei $n .^{\circ} 1.060 / 50$ assegura-lhe, apenas, a suspensão de sua exigibilidade por cinco anos ou até que a parte vencedora comprove não mais subsistir o estado de hipossuficiência da parte vencida.

3. Recurso conhecido e parcialmente provido.

(...)

No mérito, deve-se analisar se houve conduta ilícita por parte da ré, apta a ensejar a indenização pleiteada, caso provada a ocorrência de danos à autora. Para apreciar o pedido de reparação de danos tendo como fundamento ato que ocasionou prejuízo à requerente, faz-se necessária, primeiramente, a definição da natureza do comportamento virtualmente ilícito, ostentado pela ré, em correlação com o perseguido efeito reparador. Cumpre estabelecer se a apontada 


\section{EULÁLIA XAVIER RIBEIRO}

obrigação de reparar o dano decorre da existência de ato ilícito comissivo ou omissivo, em face das repercussões a serem geradas a partir de tal constatação. Conforme os documentos acostados aos autos, ao contrário do que alega a empresa autora, vê-se que a ré contratou exclusivamente com a empresa SMPB São Paulo, em cujo negócio jurídico estipulou-se a cessão dos direitos autorais, de forma a permitir à contratante (Terracap), o uso do material fotográfico. Como se vê dos documentos anexados pela própria autora (fls. 12/14), as referidas Estimativas de Custos $n^{\circ} 1211 / 01,1222 / 01$ e 01332, foram, sem exceção, emitidas pela empresa SMP\&B São Paulo Comunicação Ltda. Assim, não há que se falar em conduta ilícita da empresa ré que enseje a pretendida indenização, posto que a autora, desatendendo os preceitos do art. 333, I, do CPC, deixou de comprovar ter contratado com a requerida, nos moldes apresentados na inicial. Conforme sustenta a disciplina dos direitos autorais - Lei 9.610/98 - o artigo 79 e seu parágrafo $1^{\circ}$, ao assegurar ao autor de obra fotográfica o direito de reproduzi-la, ressalva que a fotografia, quando utilizada por terceiros, indicará de forma legível o nome do seu autor. Ocorre que referida lei, ao disciplinar a transferência dos direitos do autor, dispõe que a cessão total ou parcial desses será sempre por escrito e presumir-se-á onerosa (art. 50, caput, e $\S 2^{\circ}$ ). Assim, como bem se observa do contrato estabelecido entre a ré e a empresa SMP\&B Comunicação, a cessão de direitos autorais foi realizada por escrito, com valores previamente estabelecidos.

Nos presentes autos, verifica-se que a autora cedeu as fotografias a terceiro, ou seja, à empresa SMP\&B, sendo que esta última as repassou à ré, por força de contrato estabelecido entre as partes. Observa-se que a empresa autora não pode alegar em seu favor desconhecimento do contrato estabelecido entre a ré e a empresa SMP\&B, eis que a produção fotográfica realizada foi feita não em nome da autora, mas daquela empresa (SMP\&B), conforme os documentos anexados aos autos.

Desta forma, não há como implicar ao réu, conduta ilícita que the obrigue a indenizar a autora. Ressalto que eventual uso indevido das fotografias poderá ser averiguado em face da empresa SMP\&D em ação própria eis que esta não figurou como parte nos presentes autos.

Assim, no caso estritamente examinado, verifica-se que não houve qualquer ato do réu que ensejasse a indenização pleiteada, posto que os danos morais não restaram devidamente comprovados. 
(...)

Pelos motivos acima expostos, julgo improcedente o pedido inicial. Condeno a autora ao pagamento das custas do processo e honorários advocatícios, estes arbitrados em R\$1.000,00 (um mil reais), com fulcro no art. 20, § $4^{\circ}$, do CPC. Extingo o processo com julgamento do mérito, com fulcro no art. 269 , I, do CPC". (Grifo nosso)

\section{Considerações Finais}

0 direito de autor visa garantir benefícios morais e patrimoniais aos autores de forma perene. A legislação vigente no Brasil e as Convenções internacionais possibilitam que o autor venha a exigir reparação quando seus direitos forem usurpados por outrem.

O presente estudo visou destacar a importância do Direito Autoral, disseminar o cerne de sua legislação a fim de que autores e a sociedade em geral ajustem-se diante da necessidade de reconhecer e valorizar o direito de quem cria a obra e, na medida deste conhecimento, tenham o respeito e tratem com dignidade os direitos do autor, dando-lhes os devidos créditos e os respectivos valores pecuniários que lhes é de direito.

Há de se destacar também a legislação vigente no Brasil, que serviu de base fundamental para este estudo, a Lei n. 9.610, de 19 de fevereiro de 1998, que altera, atualiza e consolida a legislação sobre direitos autorais e dá outras providências e a Lei n. 12.853, de 14 de agosto de 2013, que altera os arts. $5^{\circ}, 68,97$, 98, 99 e 100, acrescenta arts. 98-A, 98-B, 98-C, 99-A, 99-B, 100-A, 100-B e 109-A e revoga o art. 94 da Lei $n^{\circ} 9.610$, de 19 de fevereiro de 1998, para dispor sobre a gestão coletiva de direitos autorais, e dá outras providências.

Em destaque, para finalizar, as matérias julgadas quanto aos direitos morais e patrimoniais de autor citadas, demonstram a relevância de ter como garantia uma legislação específica no Brasil, que ampare o autor em seus direitos plenos, que lhes garanta continuamente os direitos morais e patrimoniais sobre suas obras e que o objetivo deste estudo seja alcançado a partir da contextualização de pontos essenciais para a mudança de comportamento da sociedade de um modo geral, minimizando controvérsias infundadas em desfavor dos autores e destacando a valorização e o reconhecimento do autor sobre a obra criada. 


\section{Referências}

ASCENSÃO, José de Oliveira. Direito autoral. 2. ed. Rio de Janeiro: Renovar, 1997.

BITTAR, Carlos Alberto. Direito de Autor. 5.ed. Rio de Janeiro: Forense, set. 2013.

BRASIL. Código Civil, de 10 de janeiro de 2012. Institui o Código Civil. Disponível em: <http://www.planalto.gov.br/ccivil_03/leis/2002//10406.htm> Acesso em:14 jun. 2014.

. Constituição Federal. Brasília: Senado Federal, 1988. Disponível em: <http://www.planalto.gov.br/ccivil_03/constituicao/constituicao.htm>. Acesso em: 9 jul. 2014.

. Lei 9.610 de 19 de fevereiro de 1998. Dispõe sobre os direitos autorais, e dá outras providências. In: Diário Oficial da República Federativa do Brasil, Brasília, DF, 19 fev. 1998. Disponível em: <http://www.planalto.gov.br/ccivil_03/ leis/l9610.htm> Acesso em: 10 jun. 2014.

. Lei $\mathrm{n}^{\circ} 12.853$ de 14 de agosto de 2013. Dispõe sobre a gestão coletiva de direitos autorais, e dá outras providências.In: Diário Oficial da República Federativa do Brasil, Brasília, DF, 15 ago. 2013. Disponível em:<http://www.planalto. gov.br/ccivil_03/_Ato2011-2014/2013/Lei/L12853.htm> Acesso em: 23 jun. 2014.

CABRAL, Plínio. A lei de direitos autorais: comentários. 5. ed. São Paulo: Rideel, 2009.

CÂMARA DOS DEPUTADOS. Decreto $n^{\circ}$ 2.577, de 17 de Janeiro de 1912. Publicação Original. Disponível em: <http://www2.camara.leg.br/legin/fed/ decret/1910-1919/decreto-2577-17-janeiro-1912-578060-publicacaooriginal-100961-pl.html> Acesso em: 12 jun. 2014.

. Lei $n^{\circ} 496$, de $1^{\circ}$ de Agosto de 1898. Publicação Original. Disponível em: <http://www2.camara.leg.br/legin/fed/lei/1824-1899/lei-496-1-agos- 
to-1898-540039-publicacaooriginal-39820-pl.html> Acesso em: 26 jun. 2014.

Lei $n^{\circ}$ 12.853, de 14 de Agosto de 2013. Publicação Original. Disponível em: <http://www2.camara.leg.br/legin/fed/lei/2013/lei-12853-14-agosto-2013-776771-publicacaooriginal-140779-pl.html> Acesso em: 23 jun. 2014.

CAMELIER, Advogados Associados Propriedade Intelectual. Direitos Autorias Convenção de Berna. Decreto $n^{\circ} 75.699$, de 6 de maio de 1975. Disponível em: <http://www.camelier.com.br/legislacao/legislacao-direitos-autorias/42/convencao-de-berna.html> Acesso em: 28 jun. 2014.

CULTURA. Lei 9.610 de 19 de fevereiro de 1998. Dispõe sobre os direitos autorais, e dá outras providências. In: Portal da Cultura, 12 jun. 2010. Disponível em <http://www2.cultura.gov.br/consultadireitoautoral/lei-961098-consolidada> Acesso em: 22 jun. 2014.

FIGUEIREDO, Fabio Vieira. Direito do Autor: proteção e disposição extrapatrimonial. São Paulo: Saraiva, 2012.

JUSBRASIL. Tribunal de Justiça do Distrito Federal e Territórios - TJ-DF - Apelação Cível: Ação de Indenização - Direito Autoral. APL 424732220068070001 DF 0042473-22.2006.807.0001. Relator: Humberto Adjunto Ulhôa. Julgamento: 29 out. 2009. Órgão Julgador: $3^{a}$ Turma Cível. 10 nov. 2009, DJ- e pág. 57.Disponível em: <http://tj-df.jusbrasil.com.br/jurisprudencia/5406683/apelacao-ci-vel-apl-424732220068070001-df-0042473-2220068070001> Acesso em: 20 jun. 2014.

- Tribunal de Justiça do Distrito Federal e Territórios - TJ-DF - Apelação Cível.Direitos Autorais. Processo: APL 809236320088070001 DF 0080923 63.2008.807.0001. Relator: Waldir Leôncio Lopes Júnior. Julgamento: 04 mai. 2011. Órgão Julgador: $2^{a}$ Turma Cível. 12 mai. 2011, DJ- e pág. 89. Disponível em: <http://tj-df.jusbrasil.com.br/jurisprudencia/18821238/apelacao-ci-vel-apl-809236320088070001-df-0080923-6320088070001 > Acesso em: 20 jun. 2014.

LEITE, Eduardo Lycurgo. Direito de autor. Brasília: Brasília Jurídica, 2004. 


\section{EULÁLIA XAVIER RIBEIRO}

SANTOS, Manuella. Direito Autoral na era digital: impactos, controvérsias e possíveis soluções. 1. ed. São Paulo: Saraiva, 2009.

VADE MECUM SARAIVA. Obra Coletiva da Editora Saraiva. PINTO, Antonio Luiz de Toledo; WINDT, Márcia Cristina Vaz dos Santos; CÉSPEDES, Livia (colaboradores). São Paulo: Saraiva, 2006.

Artigo recebido em: 30.07.2013

Revisado em: 12.08.2014

Aprovado em: 15.09.2014 